\title{
A Combined Effects Approach to the Demands-Resources- Individual Effects (DRIVE) Model of Well-Being
}

\author{
Andrew P Smith* \\ Centre for Occupational and Health Psychology, School of Psychology, Cardiff University, 63 Park Place, \\ Cardiff, CF10 3AS, U.K.
}

*Corresponding Author: Andrew P Smith, Centre for Occupational and Health Psychology, School of Psychology, Cardiff University, 63 Park Place, Cardiff, CF10 3AS, U.K.

\begin{abstract}
This article starts with approaches that examine single concepts and suggests this is not representative of the real-life situation. Theoretical approaches based on several dimensions are then discussed, with detailed coverage of the Demand-Resources-Individual Effects (DRIVE) model. Empirical research on the combined effects of occupational risk factors is also discussed. The well-being process model covered positive and negative predictors, appraisals and outcomes. The effects of the predictors are mainly independent and can be combined into a single score. The impact of new potential predictors can then be assessed with control for established predictors. The outcome measures can also be combined into a single score. Analysis of the individual components of the well-being process can still be made, but the single predictor and single outcome approach are simple and ideal for inclusion in studies examining the effect of other factors on well-being.
\end{abstract}

Keywords: Well-being; Combined Effects; DRIVE Model; Positive Well-being; Negative Well-being.

\section{INTRODUCTION}

The WHO has stated that there is more to health than the absence of disease. This has led to researchers focusing on the quality of life and well-being. The present article traces the research journey to the current approach to well-being. The general features of the present approach are introduced here, followed by the path taken to develop the methodology. The article ends with some examples that have used these methods and some recommendations for future research.

The current approach has led to the development of a questionnaire that measures well-being. It can be used with different populations, with only slight changes needed to address specific contextual issues. For example, the questionnaire for workers and students is very similar, but there are different questions relating to the sources of stress in those groups. Practical issues played a large part in the development of the measuring instrument. Long questionnaires often lead to poor compliance, so the use of short measures was essential. Different types of research require different measures. Initially, one needs a short survey to determine whether well-being is an issue. This has led to the development of both short and long versions of the questionnaire. The longer version provides a more detailed profile of well-being and is preferable for research.

The development of the questionnaire has an underlying theoretical model. The general structure of the model is that it covers factors, both external and internal, that influence well-being, appraisal of well-being (e.g. perceptions of stress or life satisfaction), and both positive (e.g. happiness, positive affect) and negative (e.g. anxiety, depression and negative affect) outcomes. A central feature of the present article is the method of analysis of such data. The current approach starts by combining predictor variables and examines associations with a single outcome. Further analyses of the microstructure of the associations allow one to identify key factors which need to be addressed to improve well-being.

The current model is a simplification of a more complex process. Other variables, both predictors and outcomes, can be added to the model. In the analyses, the combined effects of the established predictors are co-varied, and the new variables examined. If the new variables add additional predictive power, they become established factors that, provided their effects can be replicated, develop the sophistication of the model of well-being. 
A Combined Effects Approach to the Demands-Resources-Individual Effects (DRIVE) Model of WellBeing

\subsection{Individual Factors Influencing Health and Safety}

Initial research in the area of health and safety examined potential risk factors in isolation. This does not reflect the real-life situation where the person is exposed to a combination of different factors. A good example of the individual factor approach can be seen in research on the effects of noise (Smith \&amp; Broadbent, 1991; Smith, 1989, 1990, 1991; Smith \&amp; Jones, 1992). If one examines research on noise and accidents at work, one finds that the early research aimed at identifying associations between the two. However, it was apparent that noisy workplaces have other negative features (e.g. the presence of dangerous machinery). This led to laboratory studies of controlled noise exposure or epidemiological studies that statistically controlled for other factors but did not look at the combined effects of the different potential risks. A similar approach occurred in the area of working hours (Folkard \&amp; Monk, 1985; Smith, 1992). This research did identify that the effects of the work schedule depended on the characteristics of the person and the task they were carrying out.

\subsection{Laboratory Studies of Combined Effects}

Studies in the 1980\&\#39; s examined the combined effects of noise and night-work on performance efficiency and mood (Smith, 1986; Smith \&amp; Miles, 1987a, b). The results demonstrated significant effects of both variables, but they were independent, and few interactions between noise and night- work were observed. Health Psychology then started to develop more sophisticated models of health, and these were examined in studies examining psychosocial factors and susceptibility to the common cold. Of primary interest were the potential association between stress and susceptibility to experimentally induced infection (with upper respiratory tract viruses) and illness (Cohen, Tyrrell, \&amp; Smith, 1991, 1993; Cohen et al., 1993). The combined stress score (negative life events + perceived stress + negative affect) was related to susceptibility to infection and illness in a linear dose-response. Secondary analyses showed that the different components of the combined effects score influenced different biological mechanisms. Life events were related to an increased risk of developing symptoms, whereas perceived stress and negative affect increased the risk of infection.

\subsection{The Demands-Control-Support Model}

One of the significant developments in occupational health psychology was the Demands-Control model (Karasek, 1979). This model identified the importance of job demands and control over work. The novel prediction was that it was the combination of high demands and low control that would lead to the most negative outcomes. Social support was a later addition to the model (Johnson \&amp; Hall, 1988), with research showing that appropriate support could buffer against the effects of high demands. More recent research demonstrates the effects of demands, control and support, but shows that their effects are mainly independent (de Lange et al., 2010). Other approaches have stressed the importance of combinations of factors, with Effort-Reward imbalance (Siegrist et al., 2004) being a popular model.

\subsection{Combined Effects of Occupational Risk Factors}

This research (Smith, McNamara \&amp; Wellens, 2004) had five main aims. The first was to review the literature on the combined effects of occupational hazards on health and safety. Secondly, to conduct secondary analyses of self-report data from randomly selected community samples (Smith et al., 2000) to examine associations between combinations of workplace factors on health and safety. Thirdly, to examine the effects of combinations of workplace factors on accidents at work in a sample attending Accident and Emergency. Fourthly, to investigate the effects of combinations of workplace factors on performance efficiency and physiology. Finally, apply the approach to other current topics of interest and review the implications of the results for policy issues such as the HSE stress management standards (Mackay et al., 2004). 
A Combined Effects Approach to the Demands-Resources-Individual Effects (DRIVE) Model of WellBeing

The results showed that there was little existing literature on the combined effects of occupational risk factors (Smith \&amp; Mackay, 2001). The secondary analyses showed that combinations of workplace factors (the Negative Occupational Factors Score) were associated with health and safety outcomes, and many of the associations were consistent across different industry sectors (Smith et al., 2001). An example is shown in Table 1, with perceived occupational stress as the outcome and quartiles of the combined effect score as predictors. The results show a linear relationship between total negative job characteristics and perceived stress at work.

Table1. The total negative factors score (split into quartiles, first quartile = lowest number of negative factors, the fourth quartile = highest) and occupational stress (being in the high-stress category, defined as reporting being very or extremely stressed in work).

\begin{tabular}{|l|l|l|}
\hline & OR & CI \\
\hline 1stQuartile & 1.00 & \\
\hline 2ndQuartile & 1.60 & $1.32-1.93$ \\
\hline 3rdQuartile & 2.08 & $1.72-2.53$ \\
\hline 4thQuartile & 3.84 & $3.17-4.66$ \\
\hline
\end{tabular}

Some of the associations between the negative factors score and outcomes were due to stress mediation. Negative occupational factors combined with demographic characteristics to increase the risk of stress and minor injuries at work. Dissection of the negative occupational factors scores identified outcomes influenced by job demand-control-support, physical hazards/working hours, and effort-reward imbalance. Certain outcomes were associated with all predictors, others by pairs of predictors and some were only associated with a specific dimension. Stress at work was associated with all predictors, but a combination of high demands/high effort had the most significant effect. Analyses of longitudinal data confirmed results from the cross-sectional analyses and gave a better indication of causality. The Accident and Emergency Unit study results revealed that the negative occupational factors score was also associated with work accidents.

Similarly, combinations of occupational factors were associated with objective measures of performance and physiology (Wellens \&amp; Smith, 2006). The present approach has also been applied to specific problems in certain occupations (e.g. seafarers\&\#39; fatigue, Smith et al., 2006; McNamara \&amp; Smith, 2020; Wellens et al., 2020) and in assessing the association between drug use and safety at work (Smith et al., 2004a, b). It has substantial implications for developing stress management standards, an approach used by the U.K. Health and Safety Executive to prevent and manage stress at work.

\section{The Demands-Resource-Individual EfFects (Drive) Model}

The combined effects approach focused on combinations of job characteristics. Other research (Smith et al., 2000) showed that demographic factors and type of job (e.g. part-time v full-time) also had additive effects, with the combined score having a linear dose-response with outcomes like occupational stress. The subsequent development (Mark \&amp; Smith, 2008) led to individual characteristics, such as coping styles, being added to the Demands-Resources model. This model is shown in Figure 1. It has many features of earlier models of stress but puts a greater emphasis on individual characteristics and personal resources. The basic model included factors from the DemandControl-Support model (DCS) model, attributional explanatory styles, coping behaviours, and outcomes such as anxiety, depression, and job satisfaction. The model was intended as a general framework into which study relevant variables could be added. The simple DRIVE model proposed direct effects of the predictor variables on outcomes and moderation of the effects of demands by individual differences and resources. The enhanced DRIVE model included perceived stress and other interactive effects. Research using the DRIVE model has shown direct effects of the predictor variable groups on outcomes but little support for interactions (Mark \&amp; Smith, 2011, 2012). Research has also shown that certain effects of job characteristics are mediated through perceived stress (Galvin, 2016; Nelson, 2017). 
A Combined Effects Approach to the Demands-Resources-Individual Effects (DRIVE) Model of WellBeing

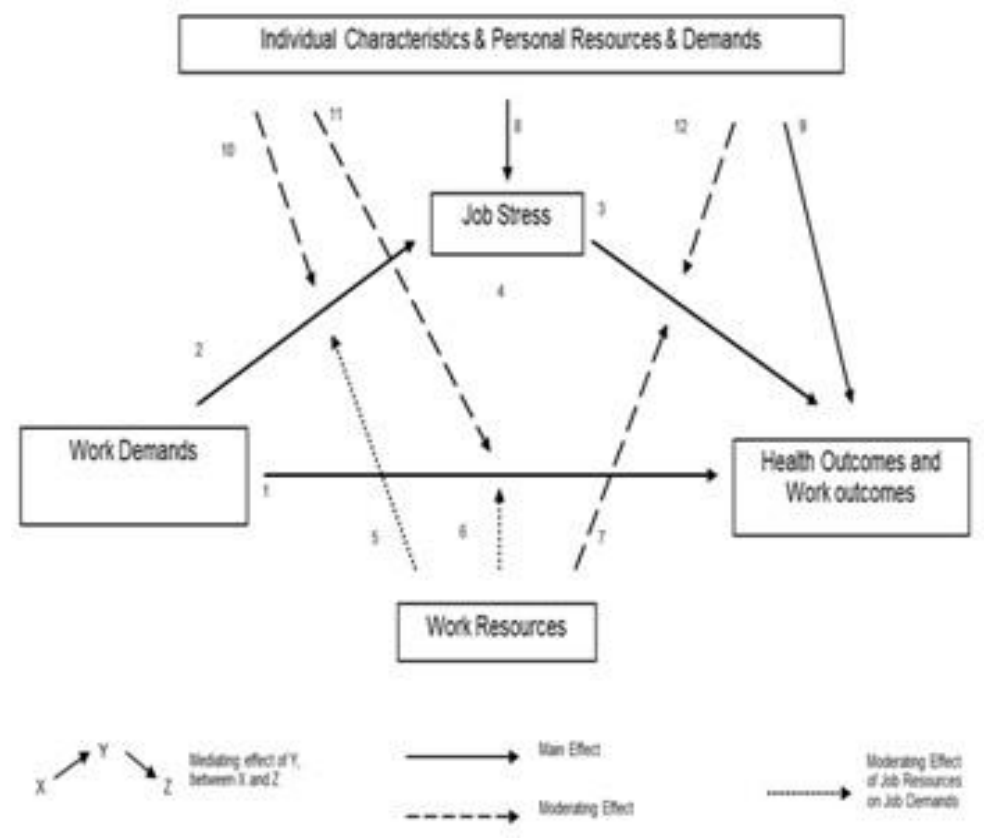

Figure1. The Demands-Resources-Individual Effects (DRIVE) model

\section{WELL-BEING AT WORK}

Some researchers (e.g. Wadell \& Burton, 2006) have argued that "Work is good for you" However, a literature review shows that it is the absence of work that is bad. Work per se is not necessarily good but good work is good for you (Smith \&amp; Wadsworth, 2011). This then leads one to the question of "What is a good job" or what psychosocial characteristics underlies the association between work and positive outcomes. A literature review (Wadsworth et al., 2010) showed that there is very little published evidence on its positive effects compared to the negative effects of work. Indeed, the literature on positive aspects has many problems, such as a lack of theory, lack of data to support views and weak methodology. Measures of well-being are mainly outcomes and do not reflect the "well-being process", which is necessary to understand the topic.

Secondary analyses of large-scale surveys (Wadsworth, Chaplin \&amp; Smith, 2010) compared the effects of the presence and absence of positive/negative job characteristics. For example, the analyses considered questions such as: "Is the presence of social support good, the absence of social support bad, or are both true" This was done by splitting the scores into tertiles (three equal parts), using the mid-value as the reference value, and examining whether equal and opposite changes occurred at opposite ends of the continuum. The results from these analyses showed that dose-response did not occur for all types of association. This shows that one must examine both ends of the continuum - the presence of positive features and the absence of negative features - rather than inferring the effects of one from the other. Additional survey data, including positive job characteristics, appraisals and outcomes, were also collected (Smith et al., 2011). The primary question addressed was what predicts positive outcomes? Again, a combined effects approach was used, and the "good job score", which best predicted positive outcomes (e.g. good health; well-being), was calculated by the sum of positive job characteristics/appraisals and the absence of negative characteristics/appraisals. An example of this is shown in Table 2. This shows that those with the highest good job score were nearly 23 times more likely to be in the high positive health group than those in the lowest good job category

Table2. Associations between the good job score (shown as quartiles) and positive mental health (a median split into high/low groups)

\begin{tabular}{|c|c|}
\hline & Odds Ratio \\
\hline Low good job & 1.00 \\
\hline Second quartile & 2.89 \\
\hline Third quartile & 5.24 \\
\hline High good job & 22.83 \\
\hline
\end{tabular}


This research on "What is a good job" showed that a multi-dimensional model of well-being at work is required and that it should measure a wide range of job characteristics, job attitudes, individual characteristics and outcomes. This has been addressed by developing surveys involving short measures of many concepts, and an example which led to the development of the Wellbeing Process Questionnaire (WPQ), which has been used in research on many of the above issues (Williams \&amp; Smith, 2012).

\section{The Well-Being Process Model}

Well-being involves many different factors and is often difficult to define. The "well-being process Model" involved a holistic approach to well-being (Williams \& Smith, 2012) which provided a theoretical framework and a measuring instrument used in policy and practice. The approach was based on the Demands-Resources-Individual Effects (DRIVE) model and also included positive individual characteristics (self-efficacy, self-esteem and optimism), positive appraisals (e.g. job and life satisfaction) and outcomes (e.g. happiness and positive affect). Positive outcomes are central to research on subjective well-being (Diener, 1984, 2000; Ryff \& Singer, 2008). However, it is essential to include both negative and positive components of well-being as they involve different CNS functions.

The above model led to a measuring instrument with both positive (e.g. control and support) and negative characteristics (e.g. demands), appraisals (positive: life satisfaction; negative: perceived stress), individual characteristics (e.g. negative: negative coping; positive: positive personality) and outcomes (positive: happiness, negative: anxiety and depression). The well-being process model requires measurement of many factors, which led to a very long and not acceptable questionnaire to the respondents. Short scales were developed, and these were highly correlated with the original longer scales. The single questions provide examples of the concept being measured, and responses are made using a scale of 1-10, which allows a greater potential range of responses. An example is shown below:

"Job Demands: I feel that I do not have the time I need to get my work done (for example I am under constant time pressure, interrupted in my work, or overwhelmed by responsibility or work demands)" Response: on a 10-point scale from Disagree strongly to Agree strongly.

The Wellbeing Process Questionnaire (WPQ - Williams \&amp; Smith, 2016, 2018a, b; Williams, Pendlebury \& Smith, 2017; Williams, Thomas \&amp; Smith, 2017, and the Smith Wellbeing Questionnaire (SWELL - Smith \&amp; Smith, 2017a, b, c; Fan \&amp; Smith, 2017a, 2017b, 2018) were developed in this way, with SWELL having a more comprehensive range of outcomes related to health and performance efficiency. The questionnaires were also modified for use with students (Williams, Pendlebury, Thomas \&amp; Smith, 2017; Alharbi \& Smith, 2019; Nor \& Smith, 2019). The WPQ has good reliability and validity. It has been used in cross-sectional research and also longitudinal studies, which can identify causal relationships (Galvin, 2016; Nelson, 2017). An initial study with university staff revealed significant correlations between the new short items and the original full scales (e.g. average for personality: 0.66; average correlation for work characteristics: 0.7). The predictive validity was examined by testing the Effort-Reward Imbalance and JobDemands-Control-Support models with both the long scales and the short items. Similar results were obtained with both sets of questions (i.e., the predictive validity of the short items was comparable to that of the long scales). The use of short items enables one to add more concepts to the model. Different concepts often overlap, and when they are all included in a single analysis, only some remain significant. Using this approach, the following constructs were identified as established predictors:

- Negative job characteristics: Demands; Effort; Over-commitment.

- Positive job characteristics: Rewards; Control; Support; Consultation on change; Good supervisor relationship.

- Positive life circumstances: Uplifts; Flourishing; Social Support.

- Negative life circumstances: Hassles.

- Positive Personality: Optimism; Self-esteem; Self-Efficacy; Emotional Stability.

- Negative Coping: Avoidance; Self-blame; Wishful thinking. 
Research has shown that only certain variables predict specific outcomes. For example, work characteristics were strong predictors of job satisfaction and job stress, whereas personality was a better predictor of positive and negative outcomes. Other concepts have also been added to the model. These have included other outcomes such as fatigue (Smith, 2018), sleepiness (Howells \&amp; Smith, 2019) and burnout (Omosehin \& Smith, 2019). The approaches described here have been used to address many other topics. First, research has investigated well-being at work in many different job sectors (the police; call centres; offshore; seafarers; and healthcare professionals). Second, additional constructs have been examined to see how these fit into the model (ethnicity, religion, other aspects of personality). Third, other occupational outcomes have been investigated, and predictors of them examined (accidents, musculoskeletal disorders, absenteeism, and presenteeism). The research has also been conducted in different countries to determine which effects may be culture-specific and more generic. Future research should use the approach to evaluate interventions that aim to change working practices or offer occupation support.

The most recent change in the methodology has been to adopt a more straightforward method of analysis. This was outlined in the introduction and involves using a single measure of established predictors and a single outcome score. It is essential to point out that one can still examine the microstructure of well-being by looking at individual variables (Smith \&amp; Firman, 2019). However, the new approach is primarily intended to assess the impact of new variables, and two examples are now given.

\section{THE CURRENT APPROACH}

The above account has traced the development of the well-being process approach. One obvious development is that the versions for workers and students are now somewhat different from the original versions. The latest versions are available on Research Gate. Both long and short versions have been developed, the short versions being instrumental when other topics are measured in the survey.

The second recent development has been in the analysis of the questionnaire. Two examples of the new approach are now given, the first (Smith, in press) involving a re-analysis of an already published study, and the second (Zhang \& Smith, submitted) a preliminary study of the use of the questionnaire with a Chinese sample.

\subsection{A Secondary Analysis of the Well-Being of Nurses}

The original analysis of this study demonstrated the reliable effects of the established well-being predictors on the positive and negative well-being outcomes. The secondary analyses aimed to compare the predictive power of a combined risk factors score (combing organisational and personal characteristics) with a measure (the Expanded Nurses Stress Scale, ENSS) covering operational issues such as interacting with relatives of patients, coping with death and dying, and interactions with other members of staff, and with the extent to which they were flourishing, and had recent hassles in their daily life.

The study had a sample of 178 nurses. The predictors of well-being (job resources, job demands, social support, positive personality, and coping styles) were combined into a single score (negative predictors - positive predictors). The outcomes were also combined to give a single well-being score (negative outcomes-positive outcomes).

Initial analyses showed significant correlations between the predictor variables and the well-being outcome. A regression analysis, with the well-being outcome as the dependent variable, revealed a significant effect of the combined predictor score but showed that the ENSS score was no longer significant. The new measures, hassles and flourishing, had significant additional effects on wellbeing.

The combined effects of established predictors of well-being were highly significant in this study. The association of the ENSS score with well-being could be accounted for by the combined effects score. Hassles and flourishing scores significantly affected well-being, even when the combined effects score was included in the model. This suggests that they should be added to the WPQ as they add to the overall predictive power. 
The following study continued using the combined predictor score and assessing the impact of new variables.

\subsection{Combined Predictors of Well-Being: Job Demands and Rumination}

A flexible and holistic model of well-being is essential for understanding the topic. In the present study, the Wellbeing Process Questionnaire was translated into Chinese and an online survey of the impact of work and individual characteristics on Chinese employees\&\#39; well-being. New variables, work-related rumination and problem-solving rumination, were added to determine whether they would add to the combined predictive power of the established WPQ variables. 109 employees from a wide range of different jobs in China participated in the study. The long version of the WPQ had 38 questions covering 11 dimensions, and the short version had 13 questions.

The results revealed that the long and short versions of the scale were highly correlated and reliable. The combined predictors\&\#39; score was significantly correlated with the well-being outcome score. Analyses including both the combined predictors of the score and the rumination scores showed that affective rumination negatively affected positive well-being, whereas problem-solving rumination was positively correlated with positive well-being. This study confirmed the importance of including the combined predictors of well-being score when assessing the effects of other factors. When this was carried out, rumination was shown to be associated with well-being. This suggests that rumination is another dimension that will add to the predictive power of the combined WPQ predictors.

\section{CONCLUSION}

This paper aimed to describe the development of measuring and analysing well-being with a solid theoretical basis and implications for policy and practice. The research review initially covers approaches that have focused on single concepts and conclude that this is not representative of real life. Theoretical approaches using several dimensions are then discussed, and the Demand-ResourcesIndividual Effects (DRIVE) model is outlined. Empirical research examining the combined effects of occupational risk factors is also presented. The well-being process model, which includes positive and negative predictor variables, appraisals and outcomes, is presented. The predictor variables mainly have independent effects, and they can be combined into a single well-being predictor score. The impact of new potential predictors can then be assessed in analyses that control the effects of established predictors. The outcome measures can also be combined into a single score which includes both positive and negative states. This approach has been used before to examine job characteristics. A group of researchers based in Israel (Melamed et al., 1999) developed the Ergonomic Stress Level (ESL) measure. This measure included: body motion and posture, physical effort, active hazards, and environmental stressors in the workplace using a mixture of self-reports and expert ratings. Using the combined effects approach showed there was a linear relationship between the ESL measure and accident incidence. If research is focused on the current well-being process model, analysis of the individual components can still be made, but the single predictor and single outcome approach are ideal for research examining the effect of other factors on well-being. Finally, the latest versions of the well-being process questionnaires for workers and students are available for general use.

\section{REFERENCES}

[1] Alharbi, E., Smith, A.P. (2019). Studying-away strategies: A three-wave longitudinal study of the wellbeing of international students in the United Kingdom. The European Educational Researcher, 2(1), 59-77. https://doi.org/10.10.31757/euer.215

[2] Cohen, S., Tyrrell, D.A.J., Smith, A.P. (1991). Psychological stress in humans and susceptibility to the common cold. New England Journal of Medicine, 325, 606 - 612. doi: 10.1056/NEJM199108293250903

[3] Cohen, S., Tyrrell, D.A.J., Russell, M., Jarvis, M.J., Smith, A.P. (1993). Smoking, alcohol consu mption and susceptibility to the common cold. American Journal of Public Health, 83, 1277-1283. https://doi.org/10.2105/AJPH.83.9.1277

[4] Cohen, S., Tyrrell, D.A.J., Smith, A.P. (1993). Negative Life Events, Perceived Stress, Negative Affect and Susceptibility to the Common Cold. Journal of Personality and Social Psychology, 64, $131-140$. doi:10.1037//0022-3514.64.1.131 
A Combined Effects Approach to the Demands-Resources-Individual Effects (DRIVE) Model of WellBeing

[5] de Lange, A.H., Taris, T.W., Jansen, P., Kompier, M.A.J., Houtman, I.L.D., Bongers, P.M. (2010). On the relationships among work characteristics and learning-related behavior: Does age matter? J. Organiz. Behav, 31, 925-950. https://doi.org/10.1002/job.649

[6] Diener, E. (1984). Subjective well-being. Psychological Bulletin, 95(3), 542-575. https://doi.org/ 10.1037/0033-2909.95.3.542

[7] Diener, E. (2000). Subjective well-being: The science of happiness and a proposal for a national index.American Psychologist, 55(1), 34-43. doi: 10.1037/0003-066X.55.1.34

[8] Fan, J., Smith, A.P. (2017). Positive well-being and work-life balance among U.K. railway staff. OpenJournal of Social Sciences, 5, 1-6. https://doi.org/10.4236/jss.2017.56001

[9] Fan, J., Smith, A.P. (2017). The impact of workload and fatigue on performance. In L. Longo \&amp; M.C.Leva (Eds.), Human Mental Workload: Models and Applications. H-WORKLOAD 2017. Communications in Computer and Information Science. Cham: Springer 726 90-105. https://doi.org/ 10.1007/978-3-319-61061-0_6

[10] Fan, J., Smith, A.P. (2018). The mediating effect of fatigue on work-life balance and positive well-being in railway staff. Open Journal of Social Sciences, 6, 1-10. https://doi.org/10.4236/jss.2018.66001

[11] Folkard, S., Monk, T.H. (1985). (eds) Hours of Work: Temporal factors in work scheduling. Chichester: Wiley.

[12] Galvin, J. (2016). A multi-method approach to researching stress and mental health in two groups of healthcare students: nursing students and trainee clinical psychologists. PhD Thesis, Cardiff University. http://orca.mwe.cf.ac.uk/id/eprint/98616

[13] Howells, K., Smith, A.P. (2019). Daytime sleepiness and the well-being and academic attainment of university students. OBM Neurobiology, 3 (3): 1-18. doi:10.21926/obm.neurobiol.1903032

[14] Johnson, J.V., Hall, E.M. (1988). Job strain, workplace social support, and cardiovascular disease: a crosssectional study of a random sample of the Swedish working population. American Journal of Public Health, 78(10), 1336-1342. doi: 10.2105/AJPH.78.10.1336

[15] Karasek, R.A. (1979). Job Demands, Job Decision Latitude, and Mental Strain - Implications for Job Redesign. Administrative Science Quarterly, 24(2): 285-308. https://doi.org/10.2307/2392498

[16] Mackay, C., Cousins, R., Kelly, P., Lee, S., McCaig, R. (2004). Management Standards and work -related stress in the U.K.: Policy background and science. Work and Stress, 18(2), 91-112. https://doi.org/10.1080/ 02678370410001727474

[17] Mark, G.M., Smith, A.P. (2008). Stress models: A review and suggested new direction. In: Occupational Health Psychology: European Perspectives on Research, Education and Practice,Vol. 3. EA-OHP series. Edited by J. Houdmont \&amp; S. Leka. Nottingham University Press. 111-144.

[18] Mark, G., Smith, A.P. (2011). Effects of occupational stress, job characteristics, coping and attributional style on the mental health and job satisfaction of university employees. Anxiety, Stress and Coping, 25,6378. doi: 10.1080/10615806.2010.548088

[19] Mark, G., Smith, A.P. (2012). Occupational stress, job characteristics, coping and mental health of nurses. British Journal of Health Psychology, 17, 505-521. doi: 10.1111/j.2044-8287.2011.02051.x

[20] McNamara, R.L., Smith, A.P. (2020). Combined effects of fatigue indicators on the health and well-being of workers in the offshore oil industry. Journal of Health and Medical Sciences, 3 (3), 270-276. doi:10.31014/aior.1994.03.03.122

[21] Melamed, S., Yekutiell, D., Froom, P., Kristal-Boneh, E., Ribak, J. (1999). Adverse work and environmental conditions predict occupational injuries: The Israeli cardiovascular occupational risk factors determination in Israel (CORDIS) study. American Journal of Epidemiology, 150(1): 18-26. http://dx.doi.org/10.1093/oxfordjournals.aje.a009913

[22] Nelson, K. (2017). Behind the frontlines: occupational stress and well-being in Jamaican police officers. PhD Thesis, Cardiff University. http://orca.mwe.cf.ac.uk/id/eprint/99877

[23] Nor, N.I.Z., Smith, A.P. (2019). Psychosocial characteristics, training attitudes and well-being of students: A longitudinal study. Journal of Education, Society and Behavioral Science, 29(1), 1-26. https://doi.org/10.9734/JESBS/2019/v29i130100

[24] Omosehin, O., Smith, A.P. (2019). Adding new variables to the Well-being Process Questionnaire (WPQ)- Further studies of Workers and Students. Journal of Education, Society and Behavioral Science, 28(3), 1-19. doi: 10.9734/JESBS/2018/45535

[25] Ryff, C., Singer, B. (2008). Know thyself and become what you are: A eudaimonic approach to psychological well-being. Journal of Happiness Studies, 9(1), 13-39. doi: 10.1007/s10902-006-9019-0 
A Combined Effects Approach to the Demands-Resources-Individual Effects (DRIVE) Model of WellBeing

[26] Siegrist, J., Starke, D., Chandola, T., Godin, I., Marmot, M., Niedhammer, I., et al.: The measurement of effort-reward imbalance at work: European comparisons. Social Science and Medicine 58(8), 1483-1499 (2004) doi: 10.1016/S0277-9536(03)00351-4

[27] Smith, A.P. (1986). Acute effects of meals, noise and night work. British Journal of Psychology, 77, 377 389. https://doi.org/10.1111/j.2044-8295.1986.tb02204.x

[28] Smith, A.P. (1989). A review of the effects of noise on human performance. Scandinavian Journal of Psychology, 30, 185 - 206. https://doi.org/10.1111/j.1467-9450.1989.tb01082.x

[29] Smith, A.P. (1990). Noise, performance efficiency and safety. International Archives of Occupational and Environmental Health, 62, 1 - 5. https://doi.org/10.1007/BF00397841

[30] Smith, A.P. (1991). A review of the non-auditory effects of noise on health. Work and Stress, 5, $49-62$. https://doi.org/10.1080/02678379108257002

[31] Smith, A.P. (1992). Time of day effects in performance. In: Handbook of human performance Vol.3: State and Trait. (eds) A. P. Smith \&amp; D. M. Jones. London: Academic Press. pp. 217-235.

[32] Smith, A.P. (2018). Cognitive fatigue and the well-being and academic attainment of university students. Journal of Education, Society and Behavioral Science, 24(2): 1-12. doi: 10.9734/JESBS/2018/3952961

[33] Smith, A.P. (in press). A holistic approach to the well-being of nurses: A combined effects approach. Nursing Standard.

[34] Smith, A.P., Allen, P., Wadsworth, E. (2006). Seafarer fatigue: the Cardiff Research Programme. MCA: Southampton. http://orca.cf.ac.uk/48167/1/research_report_464.pdf

[35] Smith, A.P., Broadbent, D.E. (1991). Non-auditory effects of noise at work: a review of the literature. Health and Safety Executive Contract Research Report No. 30. https://www.hse.gov.uk/research/ crr_pdf/1991/crr91030.pdf

[36] Smith, A.P., Brice, C., Sivell, S., Wellens, B. (2001). The combined effects of occupational factors on subjective reports of health. In: Contemporary Ergonomic 2001. M.Hanson (ed). London: Taylor \&amp; Francis. Pp. 197-202.

[37] Smith, A.P., Brice, C., Sivell, S., Wadsworth, E., Wellens, B. (2001). The combined effects of occupational factors on objective measures of performance and health. In: Contemporary Ergonomic 2001. M.Hanson (ed). London: Taylor \&amp; Francis. Pp.203-208.

[38] Smith, A.P., Brice, C., Collins, A., Matthews, V., McNamara, R. (2000).The scale of occupational stress: a further analysis of the impact of demographic factors and type of job. HSE Contract Research Report 311. HSE Books. https://www.hse.gov.uk/research/crr_pdf/2000/crr00311.pdf

[39] Smith, A.P., Firman, K.L. (2019). Associations between the well-being process and academic outcomes. Journal of Education, Society and Behavioural Science,32(4), 1-10. doi:10.9734/JESBS/2019/v32i430185

[40] Smith, A.P., Johal, S.S., Wadsworth, E., Davey Smith, G., Peters, T. (2000). The Scale of Occupational Stress: the Bristol Stress and Health at Work Study. HSE Books Report 265/2000.https://www.hse.gov.uk/ research/crr_pdf/2000/crr00311.pdf

[41] Smith, A.P., Jones, D.M. (1992). Noise and performance. In: Handbook of human performance Vol.1: The physical environment. (eds) A. P. Smith \&amp; D. M. Jones. London: Academic Press. pp. 1-28.

[42] Smith, A.P., Mackay, C. (2001). Combined effects of occupational health hazards. In: Contemporary Ergonomics 2001; M.Hanson (ed). London: Taylor \&amp; Francis. Pp.179-184.

[43] Smith, A.P., McNamara, R., Wellens, B. (2004). Combined effects of Occupational Health Hazards. HSE Contract Research Report 287. HSE Books. https://www.hse.gov.uk/research/rrpdf/rr287.pdf

[44] Smith, A.P., Miles, C. (1987). The combined effects of occupational health hazards: An experimental investigation of the effects of noise, night work and meals. International Archives of Occupational and Environmental Health, 59, 83 - 89 (1987) https://doi.org/10.1007/BF00377682

[45] Smith, A.P., Miles, C. (1987). Sex differences in the effects of noise and night work on performance. Work and Stress, 1, 333 - 339. doi: 10.1080/02678378708258524

[46] Smith, A.P., Smith, H.N. (2017). An international survey of the well-being of employees in the business process outsourcing industry. Psychology, 8(1), 160-167. https://doi.org/10.4236/psych.2017.81010

[47] Smith, A.P., Smith, H.N. (2017). Workload, fatigue and performance in the rail industry. In L. Longo \&amp; M. C. Leva (Eds.), Human Mental Workload: Models and Applications. H-WORKLOAD 2017. Communications in Computer and Information Science. Cham: Springer. 726: 251-263. https://doi.org/ 10.1007/978-3-319-61061-0_17 
[48] Smith, A.P., Smith, H.N. (2017). A short questionnaire to measure well-being at work (Short-SWELL) and to examine the interaction between the employee and organisation. In R. Charles \&amp; J. Wilkinson (Eds.), Contemporary Ergonomics and Human Factors 2017; Chartered Institute of Ergonomics and Human Factors 200-205. https://publications.ergonomics.org.uk/publications/a-short-questionnaire-to measure-wellbeing-at-work-short-swell-and-to-examine-the-interaction-between-the-employee-and organisation.html

[49] Smith, A.P., Wadsworth, E. (2011). A holistic approach to stress and well-being. Part 5: what is a good job? Occupational Health (At Work), 8(4): 25-27.

[50] Smith, A.P, Wadsworth, E.J.K., Chaplin, K., Allen, P.H., Mark, G. (2011). The relationship between work/well-being and improved health and well-being. Report 11.1 IOSH. Leicester. https://iosh.com/ resources-and-research/resources/what-is-good-job-relationship-between-work-working-improved-healthwellbeing-2011

[51] Smith, A.P., Wadsworth, E., Moss, S., Simpson, S. (2004). The scale and impact of drug use by workers. HSE Research Report 193. HSE Books. https://www.hse.gov.uk/research/rrpdf/rr193.pdf

[52] Smith, A.P., Wadsworth, E., Moss, S., Simpson, S. (2004). The scale and impact of medication use by workers. HSE Research Report 282. HSE Books. https://www.hse.gov.uk/research/rrhtm/rr282.htm

[53] Waddell, G., Burton, A.K. (2006). Is work good for your health and well -being? The Stationery Office, Norwich. https://assets.publishing.service.gov.uk/government/uploads/system/uploads/attachment

[54] Wadsworth, E.J.K., Chaplin, K., Allen, P.H., Smith, A.P. (2010). What is a Good Job? Current Perspectives on Work and Improved Health and Well-being. The Open Health \&amp; Safety Journal, 2, 915. doi: 10.2174/1876216601002010009

[55] Wadsworth, E.J.K., Chaplin, K., Smith, A.P. (2010). The work environment, stress and well-being. Occupational Medicine, 60: 635 -639. doi: 10.1093/occmed/kqq139

[56] Wellens, B.T., McNamara, R., Ellis, N., Smith, A.P. (2020). Combined effects of occupational noise exposure and shiftwork on performance tasks in a seafaring population. International Journal of Humanities Social Sciences and Education, 7 (7), 150-156. http://dx.doi.org/10.20431/2349-0381.0707017

[57] Wellens, B.T., Smith, A.P. (2006). Combined workplace stressors and their relationship with mood, physiology, and performance. Work and Stress, 20, 1-14. doi: 10.1080/02678370601022712.

[58] Williams, G., Pendlebury, H., Smith, A.P. (2017). Stress and well-being of nurses: An Investigation using the Demands-Resources- Individual Effects (DRIVE) model and Well-being Process Questionnaire (WPQ). Open Access Journal of Depression and Anxiety, 1:1-8. https://orca.cardiff.ac.uk/107636/

[59] Williams, G., Pendlebury, H., Thomas, K., Smith, A.P. (2017). The student well-being process questionnaire (Student WPQ). Psychology, 8, 1748-1761. https://doi.org/10.4236/psych.2017.811115

[60] Williams, G.M., Smith, A.P. (2012). A holistic approach to stress and well-being. Part 6: The Wellbeing Process Questionnaire (WPQ Short Form). Occupational Health (At Work), 9(1): 29-31.

[61] Williams, G.M., Smith, A.P. (2016). Using single-item measures to examine the relationships between work, personality, and well-being in the workplace. Psychology: Special Edition on Positive Psychology, 7, 753-767. https://doi.org/10.4236/psych.2016.76078

[62] Williams, G.M., Smith, A.P. (2018). A longitudinal study of the well-being of students using the student well-being questionnaire (WPQ). Journal of Education, Society and Behavioral Science, 24(4), 1-6. https://doi.org/10.9734/jesbs/2018/40105

[63] Williams, G.M., Smith, A.P. (2018). Diagnostic validity of the anxiety and depression questions from the Well-Being Process Questionnaire. Journal of Clinical and Translational Research, 4(2), 101-104 https://doi.org/10.18053/jctres.04.201802.001

[64] Williams, G., Thomas, K., Smith, A.P. (2017). Stress and well-being of university staff: An investigation using the Demands-Resources- Individual Effects (DRIVE) model and Well-being Process Questionnaire (WPQ). Psychology, 8, 1919-1940. https://doi.org/10.4236/psych.2017.812124

[65] Zhang, J., Smith, A.P. A new perspective on the effects of different types of job demands on the well being of a sample of Chinese workers: The survey. ResearchGate. doi: 10.13140/R.G.2.2.20424.85768

[66] Zhang, J., Smith, A.P. (submitted). A new perspective on effects of different types of workload on the well-being of a sample of Chinese workers. 
AUTHOR'S BIOGRAPHY

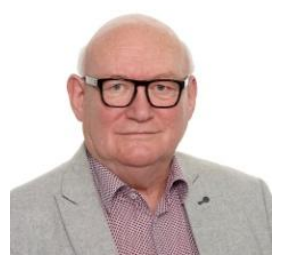

Andy Smith, is Professor of Psychology and Director, Centre for Occupational and Health Psychology, Cardiff University. He conducts research on stress at work, the working environment, transport fatigue, nutrition and behaviour, the psychology of acute and chronic illness, and wellbeing. He has published over 500 papers and given over 200 invited talks and conference papers. He completed his undergraduate degree and $\mathrm{PhD}$ at University College London and then held positions at Oxford University, the MRC Perceptual \& Cognitive Performance Unit, the University of Sussex, and the University of Bristol. He has been in his present position since 1999.

Citation: Andrew P Smith. "A Combined Effects Approach to the Demands-Resources-Individual Effects (DRIVE) Model of Well-Being" International Journal of Humanities Social Sciences and Education (IJHSSE), vol 8, no. 9, 2021, pp. 28-38. doi: https://doi.org/10.20431/2349-0381.0809004.

Copyright: () 2021 Authors. This is an open-access article distributed under the terms of the Creative Commons Attribution License, which permits unrestricted use, distribution, and reproduction in any medium, provided the original author and source are credited. 